\title{
Escapable-inescapable shock and body weight loss
}

D. M. RAGUSA, K. M. SHEMBERG, and W. RASBURY, Bowling Green State University, Bowling Green, Ohio 43402

Rats were exposed to $231 / 2 h$ of either escapable, inescapable, or nonshock conditions. Weight loss was significantly greater for inescapable Ss when compared to either escape or nonshocked Ss. These results appear to agree with prior research that has suggested an inverse relationship between stressfulness and weight gain. The data is also consistent with the hypothesis that the availability of a coping response may partially mitigate the deleterious effects of shock induced stress.

Weiss (1968) reported that yoked Ss exposed to unavoidable and inescapable shock gain less weight after the initial stress than do Ss capable of avoidance. Two questions are raised by this finding, one dealing with the sensitivity and reliability of body weight data as a dependent variable in the study of stress, and the other concerning the effects of coping responses on somatic reactions to stress. In regard to the former question, the Weiss experiment comports well with other studies in which weight gain has been used to measure the differential effect of various stress-inducing conditions (Brady, Thornton, \& DeFisher, 1962; Hale, 1964; Pare, 1965). In general, the findings tend to indicate that as the presumed stressfulness increases, weight gain will decrease. In most cases, however, the relationship between body weight changes and stress has been observed in chronic experiments using widely spaced, inescapable shock. As used here, chronic refers to the fact that exposure to the stressor takes place over a number of days, ranging from eight to 22 days for the experiments cited above. The differences between the acute (single session) and chronic experiment could be of importance in that, at least in some cases, stress-induced body weight changes may be due to an inhibition of consummatory behavior (Pare, 1965). If body weight changes are contaminated by differences in eating and drinking then the acute experiment. lacking any opportunity for consummatory behavior. may be the optimal research strategy if it can be shown that weight changes do occur in an acute experiment. If, within a single session, Ss did display differential weight loss. this would suggest that the observed changes may be due to the effect of stress per se, and not the result of stress inhibited consummatory behavior.

In the only acute experiment known to the authors to have presented weight loss data immediately following exposure to stress. Weiss (1968) found that avoidance and yoked Ss lost similar amounts of weight after a 70-trial procedure lasting 2.5-3.0 h. Examination of the avoidance performance data suggests, however. that the avoidance and yoked Ss were exposed to a modest amount of stress. After five shaping trials using $.5 \mathrm{~mA}$. the avoidance Ss made an average of 2.9 errors out of 10 trials at $.5 \mathrm{~mA}$ and an average of 4.9 errors out of 55 trials at $3.0 \mathrm{~mA}$. Thus the relatively moderate stress coupled with the presumably greater physical effort expended by avoidance Ss in executing an avoidance response of jumping onto a raised platform may have obscured the appearance of a stress induced. differential weight loss.

With regard to the question of the coping responses, Weiss (1968) presents evidence suggesting that, in the case of the rat. the availability of coping (avoidance) responses seems to ameliorate the physiological symptoms of stress. If the effect observed by Weiss has any generality, it should be possible to demonstrate weight differences between escapable and inescapable $S s$ in an instrumental escape situation as well as one using an avoidance task. Thus, the purpose of the present experiment is to examine the effect of escapable, inescapable, and nonshock conditions on weight loss in an acute experiment using closely spaced shock presentations.

Subjects

The Ss were 24 Sprague-Dawley male rats ranging in age from 88 to 100 days at the time of testing. Animals were assigned to one of eight triads on the basis of weight, the largest difference between the lightest and heaviest $S$ in any one triad being $8 \mathrm{~g}$. Within each triad Ss were assigned randomly to one of three conditions.

Apparatus

Experimental chambers were three Lehigh Valley Electronics (LVE) 1578D cages. The grids of two of the chambers were wired in parallel to one Grason-Stadler E1064GS shock generator. One of the cages wired for shock contained an LVE 1606 omnidirectional lever with a paddle attached, while the other cages had no manipulandum. All contingencies were automatically programmed with electro-mechanical devices. Masking noise was provided by a Grason-Stadler $455 \mathrm{C}$ noise generator.

Procedure

All Ss were weighed immediately prior to the testing session. Escape animals (Group E) were trained in lever press escape using an "immediate release" procedure (Dinsmoor, 1968). This procedure requires a release response if $S$ is holding the bar at the time of shock onset or a press-release sequence if $S$ is not bar-holding. Either response terminated shock and delayed subsequent shock presentation for $10 \mathrm{sec}$. Escape training began with a shock intensity of $.5 \mathrm{~mA}$. The intensity was gradually increased reaching a value of $1.6 \mathrm{~mA}$ by the end of the first hour. Three hours after the beginning of the session the intensity was raised to a final value of $2.0 \mathrm{~mA}$. The experimental session lasted $231 / 2 \mathrm{~h}$.

Group $Y$ animals were yoked to Group E Ss, thereby exposing the $Y$ Ss to inescapable shock of the same pattern, duration, and physical intensity. Group C (nonshock control) Ss remained in a test cage for $231 / 2 \mathrm{~h}$ during which time they were not exposed to shock. Throughout the entire session, all test cages were in a dimly lit room with a $70 \mathrm{~dB}$ masking noise continuously present. No food or water was available during the experiment. All Ss were immediately weighed to the nearest gram upon termination of the session.

$$
\text { RESULTS }
$$

Table I presents the summary data for the various weight measures. A t test for correlated means, using the percentage weight lost during testing. revealed : significant difference between the $Y$ and $E$ groups $(t=3.39, d f=7, p<.02)$. In only one triad did an $E$ animal lose more weight than the matched Y S. Comparisons of the nonshock control group with the $Y$ and $E$ groups were also significant $(t=12.63$. $\mathrm{df}=7 . \mathrm{p}<.01$ and $\mathrm{t}=12.06 . \mathrm{df}=7 . \mathrm{p}<.01$, respectively). In all cases. the escapable and inescapable Ss lost more weight than their matched $\mathrm{C}$ animals.

\section{DISCUSSION}

Probably the most interesting aspect of the present experiment is the ability to produce differential stress induced weight changes in an acute experiment. Previous research has also shown reliable weight changes, however. this effect appears most clearly after a few days (Brady et al. 1962: Pare. 1965) or a number of hours after the initial stress experience (Weiss. 1968). In the two experiments in which eating and drinking data have been reported (Pare \& Weiss), evidence for the differential inhibition of consummatory behavior has been present. Therefore, it is unclear whether the weight data reflect the direct effect of stress or a stress phenomenon 
Table 1

Means and Standard Deviations of Pretest and Posttest Body Weight in Grams and Percentage Body Weight Lost During Testing

\begin{tabular}{|c|c|c|c|c|c|c|}
\hline \multirow{2}{*}{ Group } & \multicolumn{2}{|c|}{ Pretest Weight } & \multicolumn{2}{|c|}{ Posttest Weight } & \multicolumn{2}{|c|}{ Percentage Lost } \\
\hline & Mean & SD & Mean & SD & Mean & SD \\
\hline \multirow{3}{*}{$\begin{array}{l}\text { Escape } \\
\text { lnescap- } \\
\text { able } \\
\text { Non-shock }\end{array}$} & 352.25 & 14.31 & 300.75 & 15.18 & 14.63 & 2.33 \\
\hline & 350.88 & 13.75 & 294.50 & 13.68 & 16.08 & 1.59 \\
\hline & 350.00 & 15.89 & 319.75 & 18.06 & 8.67 & 1.98 \\
\hline
\end{tabular}

mediated by reduced food and water intake. Since the present experiment involved a single $231 / 2$ h session in which no food or water was present, it seems to have isolated stress induced weight changes from the effects due to differential consummatory activity.

One possible reason for the success of the present approach is the use of a high density shock schedule. Prior research has tended to use a more widely spaced shock schedule in which the average time between successive shock presentations has been approximately 15 min (Brady et al, 1962; Pare, 1965). This factor of shock density agrees with the trend noticeable in the Brady et al study in which the stress induced weight changes were attenuated as the frequency of shock exposure was decreased from one shock presentation every 15 min to one every $2 \mathrm{~h}$. Differences in shock density may also explain the relative success of the present study as compared to the Weiss (1968) experiment in which avoidance and yoked Ss lost similar amounts of weight during an initial stress period. The point was previously made that the moderate amount of shock stress may have been one of the factors contributing to this finding. The fact that Weiss did eventually find differential weight gain subsequent to the initial stress may be due to the fact that low levels of stressful stimulation may selectively produce changes in weight gain without influencing weight loss. This interpretation appears to be tenable in view of the fact that Peters \& Finch (1961) found differential weight gain after only one 10-sec exposure to shock stress.

These results support the notion that body weight changes are an appropriate and useful measure of the differential effects of stress. In addition, this finding is consistent with evidence provided by Weiss (1968) in which body weight gain was less and the development of gastric ulcers was greater in a yoked unavoidable shock group than in avoidance Ss. The present study suggests that the beneficial effect of coping response is obtainable in the instrumental escape procedure as well.

Alternatively, it could be suggested that the results of the present experiment may have been due to the differential severity of shock received by the escapable and inescapable groups. This argument would consider the possibility that the escape Ss received less shock through the more sensitive forepaws since the bar was available to perch on. The inescapable Ss, without a bar present, would tend, therefore, to receive relatively more shock to the forepaws. Though no systematic data is available, all Ss were observed throughout parts of each experimental session. These observations indicated that while bar-holding was noticeable in the escape Ss, it typically emerged as a consistent response later in the session and in almost all cases involved one forepaw placed on the bar and the other on the grid floor. The inescapable Ss, on the other hand, spent extremely long periods of time standing on their hind paws with the forepaws placed against the unelectrified walls of the chamber. The only noticeable changes from this vertical position occurred very late in the session when shock duration was brief, usually ranging from .05 to $.10 \mathrm{sec}$. This new posture amounted to a horizontal orientation with the forepaws off the grid bars and folded under the rib cage. In view of the reinforcing properties of these postural accommodations to inescapable shock it would appear reasonable to assume that the sampled behavior was indicative of the kinds of behavior present throughout large segments of the experimental session.

\section{REFERENCES}

BRADY, J. P., THORNTON, D. R., \& DeFISHER, D. Deleterious effects of anxiety elicited by conditioned pre-aversive stimuli in the rat. Psychosomatic Medicine, 1962, 24, 590-595.

DINSMOOR, J. A. Escape from shock as a conditioning technique. In $M$ R. Jones (Ed.), Miami symposium on the prediction of behavior 1967: Aversive stimulation. Coral Gables: University of Miami Press, 1968. Pp. 33-75.

HALE, J. F. On the interaction effect between early experience, later response to a terminal stressor, and the presence or absence of an intervening stressor. Journal of Comparative \& Physiological Psychology, 1964, 57, 451-452.

PARE, W. P. Stress and consummatory behavior in the albino rat. Psychological Reports, 1965, 16, 399-405.

PETERS, J. E., \& FINCH, S. B. Short- and long-range effects on the rat of a fear-producing stimulus. Psychosomatic Medicine, 1961, 23, 138-152.

WEISS, J. M. Effects of coping responses on stress. Journal of Comparative \& Physiological Psychology, 1968, 65, 25 1-260. 